\title{
Mild form of Poland syndrome: A case report and review of the literature
}

\section{Hafif formda Poland sendromu: Bir olgu sunumu ve literatürün gözden geçirilmesi}

\author{
Özge Gülsüm İLLEEZ ${ }^{1}$, Hayrünisa KAHRAMAN ESEN ${ }^{2}$, Aslıhan TARAKTAŞ ${ }^{1}$, Feyza ÜNLÜ ÖZKAN ${ }^{1}$, illknur AKTAŞ ${ }^{1}$
}

\section{ABSTRACT}

Poland syndrome is a rare congenital syndrome. It is characterized by absence of the pectoralis major muscle variably associated with thoracic and/or upper limb anomalies. It should be followed carefully and for a long time due to internal organ anomalies and malignancy association. In this case report, we have discussed a patient who had Poland Syndrome in the light of the literature.

Key words: Poland syndrome, congenital, pectoralis major
ÖZ

Poland sendromu nadir görülen konjenital bir sendromdur. Major pektoral kasın yokluğuna değişik düzeylerde eşlik eden toraks ve/ veya üst ekstremite anomalileri ile karakterizedir. Iç organ anomalileri ve malignite birlikteliği nedeniyle dikkatli ve uzun süreli takip edilmelidir. Biz de bu vaka sunumu ile Poland sendromlu bir vakayı literatür eşliğinde tartıştık.

Anahtar kelimeler: Poland sendromu, konjenital, pektoralis major
GiRiş

Poland sendromu (PS); pektoralis major kasının agenezi veya hipoplazisi ile karakterize, beraberinde toraks ve üst ekstremite anomalilerinin görüldüğü konjenital bir sendromdur. Çoğu vaka sporadik olmakla birlikte, nadiren değişik kalıtım paternlerine sahip ailesel geçiş de görülmektedir ${ }^{1}$. İlk kez 1841 yılında Sir Alfred Poland tarafından bir olgu sunumu ile bildirilmiştir ${ }^{2}$. Insidansı 1/7.000 ile 1/100.000 arasında değişmekte olup, çoğu kaynakta 30.000 canlı doğumda bir görüldüğü söylenmektedir. Sıklıkla erkek cinsiyette ve sağ tarafta görülmektedir ${ }^{3}$.

\section{OLGU}

Altı yaşında-erkek hasta, annesi tarafından fark edilen duruş bozukluğu nedeniyle polikliniğimize başvurdu. Aktif bir yakınması yoktu. Anne-babasında akraba evliliği yoktu. Özgeçmişinde ve soygeçmişinde bir özellik bulunmuyordu. Boy ve kilosu normal sınırlarda, motor-mental gelişme geriliği yoktu. Lokomotor sistem muayenesinde, inspeksiyonda sağ omuz düşüklüğü görülürken, omurgada kurvatur anomalisi, scapulalarda yapısal anomaliye rastlanmadı. Sağ meme başının hipoplazik olduğu, sağ göğüs yarısının sola göre deprese olduğu görüldü (Resim 1). Boyun ve omuz hareket açıklıkları tamdı. Üst ekstremitede herhangi bir yapısal deformite görülmedi. Palpasyonla pektoral kas grubunun yokluğu belirlendi. Nörolojik muayenesi doğaldı. Yapılan incelemelerde kan sayımı, rutin idrar ve biyokimyasal parametreleri normal sınırlardaydı. Ultrasonografi ile muayenede tespit edilen pectoralis major ve minör yokluğu teyit edildi (Resim 2). Eşlik edebilecek diğer anomaliler açısından hasta ileri incelemeye alındı. PA akciğer grafisinde akciğer parankimi ve kalp yerleşimi normal olup, kostalarda ve sternumda belirgin yapısal ano-

${ }^{1}$ University of Health Sciences, Fatih Sultan Mehmet Research and Training Hospital, Department of Physical Medicine and Rehabilitation, Istanbul, Turkey ${ }^{2}$ University of Health Sciences, Fatih Sultan Mehmet Research and Training Hospital, Department of Pediatric Surgery, Istanbul, Turkey

Yazışma adresi: Özge Gülsüm Illeez, University of Health Sciences, Fatih Sultan Mehmet Research and Training Hospital, Department of Physical Medicine and Rehabilitation, Istanbul, Turkey

e-mail: ozgeilleez@hotmail.com 
mali saptanmadı. Üriner sistem ve batın ultransonografisi, ayrıntılı kardiyak inceleme yapıldı. Herhangi bir patolojik duruma rastlanmadı.

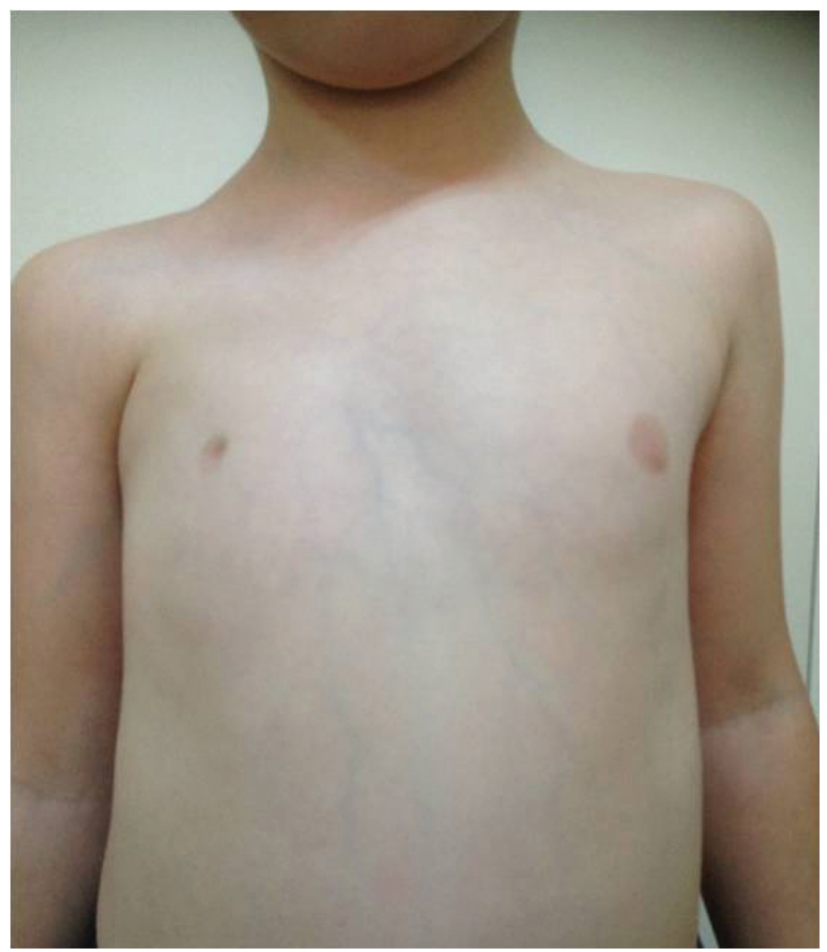

Figure 1.
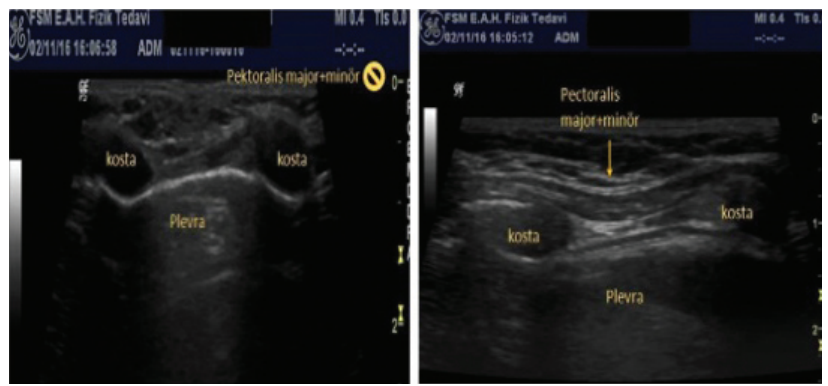

Figure 2.

\section{TARTIŞMA}

PS'nin karakteristik bulgusu pektoralis major kasının kısmen veya tamamen yokluğu olup, minör pektoral kasın ve kostaların değişen oranlarda yokluğu, meme ve/veya meme başının yokluğu veya hipoplazisi, cilt altı yağ dokusu hipoplazisi, aksillada kıllanma kaybı, radius/ulna hipoplazisi, el anomalileri (elin normalden küçük olması, sindaktili, brakisindaktili vb.) gibi göğüs kafesi ve üst ekstremite anomalilerinin yanı sıra dermatolojik anormallikler, dekstrokardi, karaciğer/bilier traktus anomalileri, üriner sistem duplikasyonu ve renal agenezi gibi bulgular hastalarda değişen oranlarda görülmektedir. Etiyolojisi tam olarak bilinmemekle birlikte intrauterin dönemde subklavian arter ve dallarının kan akımının kesintiye uğraması sonucu olduğu tahmin edilmektedir. Sendromun şiddetini ve tutulan bölgeyi kan akımının kesintiye uğrama derecesi ve kesintinin yeri belirlemektedir ${ }^{4}$.

Erkek/kadın oranı en az 3/1 olup, vakaların \%75'inde sağ taraf etkilenir ${ }^{5,6}$. Bizim vakamı da erkek cinsiyet ve sağ taraf tutulumu ile literatürle uyumluydu. Bilateral tutulum oldukça nadir olup, vaka sunumları şeklinde bildirilmiştir7. Ancak literatürden farklı olarak ülkemizden, 2015 yılında yayınlanan bir çalışmada, 113 PS'li hastadan 63'ünde sağ, 42'sinde sol ve 8 hastada bilateral yerleşim olduğu bildirilmiştir ${ }^{8}$.

PS'nin klinik bulguları çok çeşitlidir ve bu bulguların tümü aynı hastada bulunmayabilir. Ancak tanı için pektoralis major kasının agenezi veya hipoplazisi yanında diğer bulgulardan en az birinin bulunması gereklidir ${ }^{2}$. Bizim hastamızda pektoralis major kasının yokluğuna, pektoralis minör kası yokluğu, ciltaltı yağ dokusu hipoplazisi, hipoplazik meme başı bulguları eklenmişti.

Sendrom mevcut klinik bulgulara göre hafif ve ağır form olarak sınıflandırılabilir. "Pektoralis majör kasının sternokostal bölümünün yokluğu"na eşlik eden meme hipoplazisi ve meme ucu asimetrisi gibi günlük aktiviteleri kısıtlamayan basit deformiteler "Hafif Form", günlük aktivitelerde kısıtlamaya neden olan kostal, musküler eksiklikler ve üst ekstremite anomalilerinin temel bulguya eşlik ettiği olgular "Ağır Form" olarak değerlendirilir. Ağır formlar doğum sırasında tespit edilirken, hafif formlar erişkin yaşa kadar tanınmayabilir ${ }^{4}$. Biz hastamızı mevcut bulguları nedeniyle PS'nin hafif formu olarak değerlendirdik.

PS'nin birliktelik gösterdiği birçok hastalık ve sendrom bulunmaktadır. Bu nedenle hastalar klinik olarak ayrıntılı değerlendirilmelidir. PS'nin en sık görülen bulgusu göğüs kafesi depresyonu, en sık eşlik eden 
anomali Sprengel deformitesidir ${ }^{8}$. Dekstrokardi, akciğer herniasyonu, renal ve vertebral anomaliler literatürde olgu sunumları şeklinde karşımıza çıkmaktadır. Poland sendromunun dekstrokardi birlikteliği bilinmektedir. Torre M. ve ark. ${ }^{9}$ bu birlikteliği \%14, Fraser ve ark. ${ }^{10}$ ise $\% 16$ sıklıkta bulmuştur. Dekstrokardi bildirilen vakaların hemen hemen tamamında göze çarpan sendromun bu hastalarda sol taraf tutulumu göstermesi ve sağda eşlik eden kosta anomalilerinin olmasıdır ${ }^{11}$. Hastamız sağ taraf tutulumluydu ve beklendiği gibi dekstrokardisi yoktu.

Literatür incelendiğinde PS'nin çeşitli malignite türleri ile birlikteliği olgu sunumları şeklinde karşımıza çıkmaktadır. Özellikle etkilenen tarafta meme kanseri gelişimi en sık bildirilen malignensi tipidir ${ }^{12,13}$. Akciğer kanseri $^{14}$, mide kanseri ${ }^{15}$, leiomyosarkom ${ }^{16}$, Wilms tümörü ${ }^{17}$ ve lösemi ${ }^{18}$ birlikteliği görülen vakalar bildirilmiştir.

Hastada bulunan deformiteler hastanın işlevsel ve estetik sorunlarını belirler. Bu nedenle hasta bazında çözüm arayışına girilmelidir. Pektoral kasın yokluğu, latissimus dorsi ve teres major gibi çevre kaslarla kompanse edilebilir ${ }^{19}$. Bu hastalara egzersiz programı düzenleyerek kompansatuvar kaslar güçlendirilebilir ve omuz hareket açıklığı optimal hale getirilebilir. Günlük yaşam aktiviteleri kısıtlı olan ya da estetik kaygıları yoğun olan hastalarda ise cerrahi tedavi planlanmaktadır. Uygulama yaşı olarak büyüme periyodunun tamamlanması beklenmektedir. Literatürde PS'li hastaların deformitelerine yönelik pek çok cerrahi prosedür bildirilmiştir. Bu amaçla otolog kas transferi ve kosta greftleri kullanılmaktadır. Yiyit ve ark.'larının ${ }^{8}$ çalışmasında, göğüs duvarı stabilizasyonu ve optimum simetrik vücut görünümü için latisimus dorsi kas transferinin etkili bir yöntem olduğu söylenmiştir.

Sonuç olarak, PS nadir görülen bir sendrom olmasına rağmen, eşlik eden deformiteler, iç organ anomalileri ve sonradan ortaya çıkan malignensi birlikteliği nedeniyle dikkatli ve uzun dönem takip edilmesi gereken bir durumdur.

\section{KAYNAKLAR}

1. Vaccari CM, Tassano E, Torre M, et al. Assessment of copy number variations in 120 patients with Poland syndrome. BMC Med Genet 2016;17(1):89. https://doi.org/10.1186/s12881-016-0351-x

2. Fokin AA, Robicsek F. Poland's syndrome revisited. Ann Thorac Surg 2002;74:2218-25.

https://doi.org/10.1016/S0003-4975(02)04161-9

3. Ferraro GA, Perrotta A, Rossano F, D'Andrea F. Poland syndrome: description of an atypical variant. Aesthetic Plast Surg 2005;29:32-3.

https://doi.org/10.1007/s00266-004-0047-z

4. Bayramiçli M. Poland sendromu. Toraks Bülteni Dergisi 2011:229-35.

5. Urschel HC Jr. Poland syndrome. Semin Thorac Cardiovasc Surg 2009;21(1):89-94.

https://doi.org/10.1053/j.semtcvs.2009.03.004

6. Frioui S, Khachnaoui F. Poland's syndrome. Pan Afr Med J 2015;21:294.

https://doi.org/10.11604/pamj.2015.21.294.7599

7. Baban A, Torre M, Bianca S, et al. Poland Syndrome with bilateral features: case description with review of the literature. Am J Med Genet 2009;149A(7):1597-1602. https://doi.org/10.1002/ajmg.a.32922

8. Yiyit N, Işıtmangil T, Öksüz S. Clinical analysis of 113 patients with Poland syndrome. Ann Thorac Surg 2015;99(3):999-1004. https://doi.org/10.1016/j.athoracsur.2014.10.036. Epub 2015 Jan 27.

9. Torre M, Baban A, Buluggiu A, et al. Dextrocardia in patients with Poland syndrome: phenotypic characterization provides insight into the pathogenesis. J Thorac Cardiovasc Surg 2010;139:1177-82.

https://doi.org/10.1016/j.jtcvs.2009.08.024

10. Fraser FC, Teebi AS, Walsh S, et al. Poland sequence with dextrocardia: Which comes first? Am J Med Genet 1997;73:194-196. https://doi.org/10.1002/(SICI)1096-8628(19971212)73:2 $<194:: A I D-A J M G 16>3.0 . C 0 ; 2-L$

11. Lacorte D, Marsella M, Guerrini P. A case of Poland Syndrome associated with dextroposition Ital. J Pediatr 2010;36:21. https://doi.org/10.1186/1824-7288-36-21

12. Katz SC, Hazen A, Colen SR, et al. Poland's syndrome and carcinoma of the breast: a case report. Breast J 2001;7(1):56-9. https://doi.org/10.1046/j.1524-4741.2001.007001056.x

13. Zhang F, Qi X, Xu Y, et al. Breast cancer and Poland's syndrome: a case report and literature review. Breast J 2011;17(2):196-200. https://doi.org/10.1111/j.1524-4741.2010.01042.x

14. Ahn MI, Park SH, Park YH. Poland's syndrome with lung cancer. A case report. Acta Radiol 2000;41(5):432-4. https://doi.org/10.1080/028418500127345875

15. Kurt Y, Demirbas S, Uluutku AH, et al. Poland's syndrome and gastric cancer: report of a case. Eur J Cancer Prev 2006;15(6):480-2.

https://doi.org/10.1097/01.cej.0000198898.47926.8b

16. Shaham D, Ramu N, Bar-Ziv J. Leiomyosarcoma in Poland's syndrome. A case report. Acta Radiol 1992;33(5):444-6. https://doi.org/10.1177/028418519203300513

17. Athale UH, Warrier R. Poland's syndrome and Wilms tumor: an unusual association. Med Pediatr Oncol 1998;30(1):67-8. https://doi.org/10.1002/(SICI)1096-911X(199801)30:1 $<67:$ :AID-MPO16>3.0.CO;2-5

18. Parikh PM, Karandikar SM, Koppikar S, et al. Poland's syndrome with acute lymphoblastic leukemia in an adult. Med Pediatr Oncol 1988;16(4):290-2. https://doi.org/10.1002/mpo.2950160415

19. Lee YH, Chun S. Congenital absence of pectoralis major. $A$ case report and isokinetic analysis of shoulder motion. Yonsei Med 1991;32:87-90. 